\title{
PRICE SCISSORS AND THE STRUCTURE OF THE ECONOMY*
}

\author{
RaAJ Kumar SaH and Joseph E. STIGLitz
}

\begin{abstract}
This paper undertakes three sets of tasks: (i) it analyzes positive and normative aspects of price scissors (the domestic terms of trade between agriculture and industry) within nonsocialist as well as socialist LDCs. The critical role of the economy's institutional features (e.g., external trade environment, wage and income determination, and wage-productivity effects) is emphasized. Certain aspects of the Soviet Industrialization Debate and subsequent collectivization are interpreted. (ii) It develops simple rules to delineate who gains and who loses (within agriculture) from changes in terms of trade. (iii) It presents powerful (and informationally parsimonious) rules for Pareto-improving price reforms for cash crops and agricultural inputs.
\end{abstract}

A basic problem faced by the early Soviet state was how best to raise the funds required if rapid capital accumulation was to be achieved. To what extent should the burden be placed on the peasants, by lowering the prices they receive for their output (relative to the prices of industrial goods), and to what extent should the burden be placed on the industrial proletariat? This question of the appropriate domestic terms of trade between the urban and rural sectors (the price scissors) was pivotal in the Soviet Industrialization Debate (1924-1928). The same question has been intensely debated in the People's Republic of China in recent years, with a widespread view that (to use the economists' language) the rural sector was too heavily taxed during the Cultural Revolution and its aftermath, and that both sectors could be made better off by reducing the size of the scissors. In fact, the question of the appropriate terms of trade has turned out to be central to most less developed countries (LDCs), whether socialist or not, simply because this question represents a fundamental tradeoff in the initial phases of development in economies in which agriculture plays an important role.

The first objective of this paper, therefore, is to analyze the incidence of the terms of trade (that is, the consequences of changing the terms of trade on those in the rural sector, on those in the urban sector, and on the investable surplus), to examine what a

*We thank Leon Podkaminer, Michael Montias, Lawrence Summers, and Gordon Tullock for their useful suggestions. We also thank two anonymous referees for their comments on an earlier version [1985b] of this paper. Financial support from the National Science Foundation is gratefully acknowledged. 
government can or cannot accomplish through its attempts to alter the terms of trade, to identify qualitative properties of the optimal terms of trade, and to relate all of the preceding to the institutional features of the economy.

Among the institutional features of the economy that we emphasize in this paper are the international trade environment faced by the country, the nature of the mechanisms that determine wages and earnings (and the government's role in wage determination), and the nature of wage-productivity effects (that is, the consequences of changes in prices and wages on the net productivity of workers). LDCs display an enormous range concerning these features; our approach here is to formulate a general model that is then specialized to analyze the positive and normative aspects of the terms of trade under various stylized assumptions concerning these institutional features.

For example, we posit that in a socialist economy, the government has the prerogative of setting the industrial wage. In contrast, in most nonsocialist LDCs, private firms and trade unions (which, in some cases, represent a privileged class of blue-collar workers) play a major role in industrial wage determination. Thus, not only is the level of industrial wage endogenous, but also it is sensitive to the prices that the industrial workforce faces. We therefore employ a general (reduced-form) formulation for urban wage determination; this can be specialized to hypotheses which postulate that the urban wage is fixed in terms of food or the industrial good, as well as to other (more plausible) hypotheses. The analysis of corresponding induced incidences of price changes is one of the important elements of the present study.

Similarly, whether LDCs should be viewed as open or closed economies has long been debated. What is critical for an analysis of the terms of trade, however, is not the level of trade (say relative to the national income) but the ability of the economy to change the level of trade at the margin. We show, for example, that if the external trade cannot be changed at the margin (for instance, because the demand for the country's exports is very inelastic in the short run, or because the country faces constraints in the international credit market which limit its ability to trade), and if the government does not have a direct control over the industrial wage (as is the case in nonsocialist LDCs), then the government has no ability to change the terms of trade. In a socialist economy, on the other hand, the terms of trade can be altered, but such changes 
must be accompanied by specific changes in the industrial wage. ${ }^{1}$ By contrast, if the economy is open at the margin, then there is additional flexibility in the economy. This, as we shall see, has important implications for the consequences of alternative terms of trade policies.

The analysis outlined above is presented in two sections. In Section I the focus is on an LDC with a mixed (nonsocialist) economy; whereas a socialist economy is considered in Section II. In the latter section we also use our analysis to interpret certain aspects of the Soviet Industrialization Debate and the subsequent collectivization.

Another objective of this paper is to address two issues of vital interest to LDCs today. The first issue concerns the intrasectoral distributional consequences of the terms of trade: which groups in the agricultural sector (landless workers, or landlords, for example) are helped or hurt by a movement of the terms of trade against, or in favor of, agriculture? This question has been a source of debate in many LDCs. ${ }^{2}$ In Section III we delineate simple conditions to determine who gains and who loses from a change in the terms of trade. We show that under plausible circumstances, a movement in the terms of trade against (in favor of) agriculture hurts (helps) everyone in this sector, whether rich or poor.

The second issue concerns controversial questions such as whether tractors should be taxed and fertilizers subsidized; more generally, how should the taxes and subsidies on different agricultural inputs and outputs be set? The answer, as one would expect, depends in part on the social welfare function, because changes in the prices of different goods have different distributional consequences. But since agreements on social weights are difficult to achieve among policy makers and government officials, it is important to identify reforms that make the society better-off without hurting anyone. We have developed here Pareto-improving rules for reform in the prices of cash crops (sugar cane and cotton, for example) and agricultural inputs (fertilizer and tractors, for example). These reforms have the further advantage in being parsimonious in the information required to implement them. Our reform

1. In an earlier paper [Sah and Stiglitz, 1984] we emphasized this case (that is, a closed socialist economy) and abstracted from wage-productivity effects.

2. In India, for instance, Mitra [1977] has argued that higher agricultural prices have a deleterious distributional effect; whereas Kalhon and Tyagi [1980] have argued that the opposite is the case. 
analysis also suggests that there is a case against taxing some cash crops and agricultural inputs, while subsidizing others. The above rules of reform are developed and analyzed in Section IV. Some of the possible extensions of the analysis in this paper are briefly discussed in the concluding section.

\section{Price Scissors in a Mixed Economy}

In this section we describe the basic model of the economy, analyze the effects of changes in the terms of trade, and interpret the qualitative properties of the optimal terms of trade. The model consists of two aggregate sectors, each producing a single aggregate good. The individuals within each sector are assumed to be homogeneous. The government controls, at most, the nominal price of the industrial good, through which it attempts to alter the terms of trade. $^{3}$ (In the model of a socialist economy considered in the next section, the government can exercise a direct control over the urban wage. The intrasectoral heterogeneity among individuals is introduced in Section III. The model is further extended in Section IV to incorporate a multitude of goods produced in each of the two sectors.)

\section{A. The Model}

Agricultural Sector. The rural and urban populations are denoted by $N^{1}$ and $N^{2}{ }^{4} A$ is the total agricultural land owned equally by homogeneous peasants. The output of the agricultural good per peasant is $X=X\left(A / N^{1}, L^{1}\right)$, and $L^{1}$ is the variable number of hours a peasant works. $\left(x^{1}, y^{1}\right)$ denote a peasant's consumption of the agricultural and industrial goods. $Q=X-x^{1}>0$, is the surplus of the agricultural good per peasant. $p$ represents the terms of trade, that is, the price of the agricultural good in terms of the (numeraire) industrial good. A peasant's budget constraint is

$$
p Q=y^{1} .
$$

If a peasant's indirect utility is denoted by $V^{1}(p)$, then from Roy's identity, $\partial V^{1} / \partial p=\lambda^{1} Q>0$, where $\lambda^{i}$ is the positive marginal utility of income of a person in sector $i . \epsilon_{Q p}^{1}=\partial \ln Q / \partial \ln p$ is the elasticity

3. Note here that the long-standing debates on price scissors (as well as the present analysis) are based on the assumption that the government cannot (does not) set two different sets of prices in the two sectors. This assumption may not be appropriate for some LDCs, like India and South Korea. Additional policy instruments, including differential pricing in the two sectors, are discussed later.

4. The superscripts 1 and 2 denote the agricultural and industrial sectors. 
of surplus per peasant with respect to its price. We assume that this elasticity is positive.

Industrial Sector. An industrial worker's consumption is denoted by $\left(x^{2}, y^{2}\right)$, and his wage rate and (fixed) labor hours are $w$ and $L^{2}$, respectively. ${ }^{5} \mathrm{~A}$ worker's budget constraint is

$$
p x^{2}+y^{2}=w L^{2} .
$$

If $V^{2}(p, w)$ denotes the indirect utility of an urban worker, then $\partial V^{2} / \partial p=-\lambda^{2} x^{2}$, and $\partial V^{2} / \partial w=\lambda^{2} L^{2} . m=w L^{2}$ denotes a worker's income, and $\epsilon_{x p}^{2}=-\partial \ln x^{2} / \partial \ln p$ and $\epsilon_{x m}^{2}=\partial \ln x^{2} / \partial \ln m$ denote, respectively, the elasticities of his consumption of the agricultural good with respect to price and income. These elasticities are positive, since consumption goods are assumed to be normal. The output of an industrial worker is denoted by $Y$. It depends on the current capital stock per worker, $k$, and the labor hours per worker, $L^{2}$.

Wage-Productivity Effects. Wage-productivity effects have been typically studied in the literature in an environment of fixed prices. A natural generalization in the context of changing prices is the reduced-form expression:

$$
Y=Y\left(k, L^{2}, p, w\right),
$$

where the last two arguments capture the effects of prices and wages on the net output of an industrial worker. ${ }^{6}$ For later use, define two numbers, $\sigma_{m}=(\partial Y / \partial w)\left(1 / L^{2}\right)$ and $\sigma_{p}=-(\partial Y / \partial p)\left(1 / x^{2}\right)$, to denote productivity gains from an increase in wage income and a reduction in the terms of trade.

Whether an increase in $p$ increases or decreases productivity cannot be predicted without additional restrictions. ${ }^{7}$ We consider here two representative specifications: (i) productivity depends on, and increases with, the level of utility; that is, $Y=Y\left(k, L^{2}\right.$, $\left.V^{2}(p, w)\right)$. In this case, $\sigma_{p}=\sigma_{m}>0$. (ii) Productivity depends on, and increases with, the consumption of food (agricultural good);

5. The analysis corresponding to variable labor hours of industrial workers can be easily worked out.

6. In Sah and Stiglitz [1985a] we show how a reduced-form wage-productivity representation such as (3) can be specialized to specific hypotheses that relate the net output of workers to labor efficiency, labor quality, and labor turnover. For economic motivations that underlie each of these hypotheses, see Stiglitz [1982], Yellen [1984], and references therein.

7. For instance, suppose that the productivity is increasing in the consumption quantities of various goods. Then an increase in the price of one good increases the consumption of some goods (gross substitutes) and reduces the consumption of other goods (gross complements). The overall effect of a price change on productivity, therefore, cannot be predicted in general. 
that is, $Y=Y\left(k, L^{2}, x^{2}(p, w)\right)$. In this case, $\sigma_{p}>\sigma_{m}>0 .^{8}$ The latter specification can be seen as a polar case of the view that productivity is "more" sensitive to food consumption than to the consumption of other goods.

Equilibrium. Since the government in a mixed economy does not control the urban wage, the urban wage is in general affected by the prices that urban workers face. We begin with the reduced-form representation:

$$
w=\bar{w}(p)
$$

As we shall see, this formulation is consistent with several alternative hypotheses concerning how the urban wage is determined; moreover, this formulation has the advantage of identifying the central implications of the endogeneity of the urban wage.

If $T_{x}$ and $T_{y}$ denote the net imports of the two goods, then trade balance implies that $T_{y}=-P T_{x}$, where $P$ is the (fixed) international price of the agricultural good. The investable surplus is $I=N^{2} Y-$ $N^{1} y^{1} N^{2} y^{2}-P T_{x}$. Substitution of (1) and (2) in the preceding expression yields

$$
I=N^{2}\left(Y-w L^{2}\right)+p\left(N^{2} x^{2}-N^{1} Q\right)-P T_{x} .
$$

The quantity balance of the agricultural good is represented by

$$
N^{1} Q(p)+T_{x}=N^{2} x^{2}(p, w) .
$$

It is apparent that if the economy faces binding trade constraints; that is, if the quantity $T_{x}$ cannot be changed at the margin (a special case of this is a closed mixed economy, where $T_{x}=$ $0)$, then the equilibrium prices and wage, $(p, w)$, are determined by (4) and (6), and the government's attempts to alter the terms of trade (by changing the nominal price of the industrial good) have no effect on this equilibrium. ${ }^{9}$ Thus,

Proposition 1. The terms of trade cannot be altered in a mixed economy that faces constraints in external trade.

The government may not be aware of its inability to alter the terms of trade, and it may attempt to do so, but such attempts

8. $\sigma_{p}-\sigma_{m}=\left(\partial Y / \partial x^{2}\right) \epsilon_{x p}^{2 u} / p$, where $\epsilon_{x p}^{2 u}$ denotes the own price elasticity of the compensated food consumption of an industrial worker. To avoid trivial details, we assume that there is some substitution possibility in consumption; that is, $\epsilon_{x p}^{2 u}>0$.

9. Except in the implausible case where the urban wage adjusts to clear the market for the agricultural good (see expression (6)) for any level of $p$ that the government might attempt to set. Such a response of the urban wage to prices means, in effect, that the government directly controls the urban wage. We analyze this case in Section II, in the context of a socialist economy. 
cannot be successful. In the rest of this section, therefore, we consider a mixed economy facing no trade constraints. Accordingly, (6) is substituted into (5) to obtain

$$
I=N^{2}\left(Y-w L^{2}\right)+(p-P)\left(N^{2} x^{2}-N^{1} Q\right) .
$$

\section{B. Effect of Price Scissors on the Investable Surplus}

The terms of trade has a direct influence on the investable surplus, and an indirect influence through the induced effect on the urban wage. That is,

$$
\frac{d I}{d p}=\frac{\partial I}{\partial p}+\frac{d w}{d p} \frac{\partial I}{\partial w} .
$$

Before we study the combined effect, however, it is instructive to look at the separate effects that the terms of trade and the urban wage have on the investable surplus. We begin with the former.

The partial derivative of (7) with respect to $p$ can be rearranged to yield

$$
\frac{\partial I}{\partial p}=N^{2} x^{2}\left[\theta-s\left\{(1-\theta) \epsilon_{Q p}^{1}+\epsilon_{x p}^{2}\right\}-\sigma_{p}\right],
$$

where $\theta=T_{x} / N^{2} x^{2}$ is the net import of the agricultural good as a fraction of its consumption in the industrial sector. A negative (positive) $\theta$ implies that the country exports (imports) the agricultural good. Also, $1>\theta$, from (6) and from $Q>0 . s=(p-P) / p$ represents the tax or subsidy rate on the agricultural good. A negative (positive) $s$ implies that the peasants are being taxed (subsidized); whereas the industrial workers are being subsidized (taxed).

The three distinct ways in which the terms of trade affects the investable surplus can be seen in the three terms within the square brackets in the right-hand side of (9). First, a higher $p$ increases or decreases the tariff revenue from the current external trade depending on whether the country is an importer or an exporter of the agricultural good. Second, a higher $p$ lowers the net import of the agricultural good (because the rural surplus is raised and the urban consumption is lowered); consequently, the tariff revenue increases or decreases depending on whether $p$ is smaller or larger than $P$. Third, a higher $p$ reduces the investable surplus because of its negative effect on productivity.

The effect of a change in urban wage on the investable surplus is represented by the partial derivative of (7) with respect to $w$. This 
derivative can be rearranged as

$$
\frac{\partial I}{\partial w}=N^{2} L^{2}\left(-1+s \alpha_{x}^{2} \epsilon_{x m}^{2}+\sigma_{m}\right),
$$

where $\alpha_{x}^{2}=p x^{2} / m$ is an industrial worker's budget share on the agricultural good. Once again, the right-hand side of (10) is easily interpreted. A higher urban wage leads to a direct reduction in the profit from industry which reduces the investable surplus; a higher urban wage increases the consumption of the rural good by industrial workers which, in turn, increases or decreases the tariff revenue depending on whether $p$ is larger or smaller than $P$; and a higher urban wage raises the investable surplus by raising the productivity of urban workers.

To analyze the overall effect of altering the terms of trade on the investable surplus, we combine (9) and (10), using (8), to obtain

$$
\begin{aligned}
\frac{d I}{d p}=-N^{2} x^{2}\left[\left\{(1-\theta)+\left(\sigma_{p}-\right.\right.\right. & \left.\left.\sigma_{m}\right)+\bar{\rho}\left(1-\sigma_{m}\right)\right\} \\
& \left.+s\left\{(1-\theta) \epsilon_{Q p}^{1}+\epsilon_{x p}^{2 u}-\bar{\rho} \alpha_{x}^{2} \epsilon_{x m}^{2}\right\}\right],
\end{aligned}
$$

where $\epsilon_{x p}^{2 u}=\epsilon_{x p}^{2}-\alpha_{x}^{2} \epsilon_{x m}^{2}>0$ is the own compensated price elasticity of the food consumption of an urban worker, $\bar{\epsilon}_{w p}=\partial \ln w / \partial \ln p$ is the elasticity of the urban wage with respect to price, and $\bar{\rho}=-1+$ $\bar{\epsilon}_{w p} / \alpha_{x}^{2}$ is a summary parameter representing the urban wage schedule.

We focus here on the urban wage determination hypothesis according to which the urban wage adjusts, in the face of changing prices, to preserve the welfare of urban workers; that is, the urban wage is determined from

$$
V^{2}(p, w)=\bar{V}^{2},
$$

where $\bar{V}^{2}$ is a parameter. This wage schedule is consistent with a setting where the urban wage is determined through a bargaining between the government and a trade union, and the union does not suffer from money illusion; that is, the union understands how the welfare of its members is affected by changes in the wage and prices. We also point out how the qualitative insights obtained from the above wage determination hypothesis can be extended to other, less plausible, hypotheses that have been employed in development economics. 
Expression (12) yields $\bar{\rho}=0$. Substituting this into (11), we obtain

$$
\frac{d I}{d p} \gtrless 0 \text { if } p \lessgtr p^{*}, \text { where } p^{*}<P \text {. }
$$

Specifically,

$$
p^{*}=P \frac{(1-\theta) \epsilon_{Q p}^{1}+\epsilon_{x p}^{2 u}}{(1-\theta)\left(1+\epsilon_{Q p}^{1}\right)+\epsilon_{x p}^{2 u}+\left(\sigma_{p}-\sigma_{m}\right)},
$$

and it is obvious from (14) that $p$ is smaller than $P$. We have thus shown

Proposition 2. When the welfare of industrial workers is preserved at some given level, then a decrease (increase) in the terms of trade increases the investable surplus if the existing terms of trade is above (below) a critical level $p^{*}$, which is below the international relative price. ${ }^{10}$

It also follows from (13) that $p^{*}$ is the level of terms of trade at which the investable surplus is maximized. ${ }^{11}$

\section{Welfare Effects ${ }^{12}$}

Recall that a lower terms of trade hurts the peasants. Since the welfare of urban workers is unaffected by a change in the terms of

10. This result holds for some other wage determination hypotheses as well; obviously, the critical level $p^{*}$ would be different for different hypotheses. Consider the food-wage hypothesis under which the urban wage is fixed in terms of food. Then $\bar{\epsilon}_{\omega p}=1$, and $\bar{\rho}=\left(1-\alpha_{x}^{2}\right) / \alpha_{x}^{2}$. Using this, we can verify from (11) that sufficient conditions for (13) to hold are that (a) $1 \geq \sigma_{m}$; that is, the wage-productivity effects are not too large (specifically, a dollar increase in an urban worker's income yields no more than a dollar increase in his net output), and (b) an urban worker's food consumption is nonincreasing in food price (which means that the substitution effect of a price change dominates the income effect; that is, $\left.\epsilon_{x p}^{2} \geq \epsilon_{x m}^{2}\right)$. Next consider the polar opposite hypothesis under which the urban wage is fixed in terms of the industrial good. In this case, $\bar{\epsilon}_{w p}=0, \bar{\rho}=-1$, and (11) shows that a sufficient condition for (13) to hold is that $\theta<0$; that is, the country is a net exporter of the agricultural good (which is what we would expect in a typical LDC).

11. Dixit and Stern [1974] have studied the investment-maximizing price under the food-wage hypothesis (described in footnote 10), but their model is a highly special case of ours. They assume that the hours of work for a peasant are fixed and equal to the work hours for an industrial worker, the urban wage equals the fixed food output of a peasant, and there are no wage-productivity effects. That is, $X$ and $Y$ are fixed; $w L^{2}=p X ; x^{1}=x^{2}$. Substitution of these into (7) yields $I=N^{2}$ $(Y-P X)-(p-P)\left(N^{1}+N^{2}\right) Q$. These assumptions, in effect, reduce a two-sector economy to a single-sector economy consisting of homogeneous individuals. The derivative of $I$ with respect to $p$ yields the corresponding result: $p^{*}=P /\left(1+1 / \epsilon_{0 p}^{1}\right)$.

12. The results in this subsection are based on the urban wage schedule (12). See Sah and Stiglitz [1985b] for an analysis of welfare effects under other wage determination hypotheses. 
trade, according to (12), the following result is immediate from (13).

Proposition 3. Any price below $p^{*}$ is Pareto inefficient.

In other words, regardless of whether the government cares about peasants or not, and regardless of how pampered or impoverished the urban workers might be compared with the peasants, both the investable surplus as well as the welfare of peasants suffer if the terms of trade is reduced below certain levels.

How high the terms of trade should be depends on how the society trades off its desire for accumulation against the welfare of peasants. To examine this tradeoff, we now turn to a normative analysis in which the current value of the discounted aggregate social welfare is represented by the Hamiltonian,

$$
H=\emptyset+\delta I,
$$

where $I$ is given by (7), $\delta$ denotes the (positive) social value of the marginal investable surplus, and $\emptyset=N^{1} W^{1}\left(V^{1}\right)+N^{2} W^{2}\left(V^{2}\right)$ is an additive social welfare function. ${ }^{13}$ Since $V^{2}$ is fixed, $d H / d p=N^{2} x^{2}$ $(1-\theta) \beta^{1}+\delta d I / d p$, in which $\beta^{i}=\lambda^{i} \partial W^{i} / \partial V^{i}$ denotes the social weight on the marginal income of an individual in sector $i$, and $d I / d p$ is given by (11), where $\bar{\rho}=0$. We equate $d H / d p$ to zero and obtain the following interior characterization of the optimal terms of trade:

$$
s=-\frac{(1-\theta)\left(1-\beta^{1} / \delta\right)+\left(\sigma_{p}-\sigma_{m}\right)}{(1-\theta) \epsilon_{Q p}^{1}+\epsilon_{x p}^{2 u}},
$$

where the ratio of social weights $\beta^{1 / \delta}$ represents the society's tradeoff between the investable surplus and the welfare of peasants. Recalling that $1>\theta$, and $\sigma_{p} \geq \sigma_{m}$, expression (16) yields the following result.

Proposition 4. (i) Peasants are taxed if the social weight on their income is smaller than that on the investable surplus. (ii) Peasants are subsidized if the social weight on their income is larger than that on the investable surplus, and if wageproductivity effects are not significant. ${ }^{14}$

13. If the welfare function is anonymous between rural and urban individuals, then the functions $W^{1}$ and $W^{2}$ are the same.

14. In fact, this result holds even if wage-productivity effects are significant, provided that they depend on a worker's level of utility. 


\section{Price Scissors in a Socialist Economy: The Soviet DeBate AND COllectivization}

Our objectives in this section are to recast the preceding analysis in the context of a socialist economy where the government exercises a direct control over the urban wage and, then, to relate this analysis to certain aspects of the Soviet debate and collectivization. A central consequence of the government's ability to control the urban wage is that, unlike in the case of a mixed economy, a socialist government can alter the terms of trade even if the external trade is constrained. If there are no constraints on external trade, on the other hand, then a socialist government can set the terms of trade and the urban wage independently of one another. We begin with the analysis of the latter case.

\section{A. An Open Economy}

Since the government can choose $w$ and $p$ independently of one another, the natural benchmark is the one where the government chooses a level of welfare for urban workers. ${ }^{15}$ Thus, Propositions 2 to 4 , and related results, hold in the present situation as well, because these results do not depend on what the level of an urban worker's welfare is, or on how this level is determined.

To examine the tradeoffs involved in the determination of the urban workers' level of welfare, we consider the interior maximum of (15) with respect to the urban wage $w$. Equating $\partial H / \partial w$ to zero, we obtain

$$
\beta^{2} / \delta=1-\sigma_{m}-s \alpha_{x}^{2} \epsilon_{x m}^{2} .
$$

The above, in combination with (16), characterizes the socially optimal $(p, w)$ which in turn yield the optimal level of welfare for urban workers.

Intuitively, one would expect the optimal urban wage (and the resulting welfare of urban workers) to be sensitive to how much the society cares about future consumption (the investable surplus) versus the present consumption. In the extreme case of an investment-maximizing society (that is, $\beta^{i} / \delta \rightarrow 0$ ), $s$ is negative from (16)

15. If the socialist government follows some other urban wage schedule (for example, keeping the urban wage fixed in terms of one of the two goods), then footnote 10 applies here as well. But the rationale for making such an assumption for a socialist government is even weaker than that for a government in a mixed economy because the former can choose a wage schedule, whereas the latter faces a wage schedule. 
and, therefore, $\sigma_{m}>1$, from (17). That is, the wage and prices faced by industrial workers in an investment-maximizing socialist economy are such that an increase in their wage would increase their net output more than proportionately. ${ }^{16}$

The above result may appear somewhat counterintuitive because the society should be willing to increase the industrial wage if it can recover, through increased productivity, more than what it paid. The reason why this is not true is that a higher industrial wage also increases the food consumption of industrial workers. This, in turn, leads to a loss in the public revenue because the optimal $p$ is lower than $P$. This indirect revenue loss makes it undesirable for an investment-maximizing society to take full advantage of the productivity gains from increasing the industrial wage.

\section{B. An Economy Closed at the Margin}

If the traded quantities are fixed at the margin, that is, if $T_{x}$ and $T_{y}$ are fixed, then a change in terms of trade must be accompanied by a particular change in the urban wage, to maintain the quantity balance (6) in the market for the agricultural good. If $\epsilon_{w p}=$ $d \ln w / d \ln p$ represents this change in wage, in an elasticity form, then a perturbation in (6) shows that

$$
\epsilon_{w p}=\left[(1-\theta) \epsilon_{Q p}^{1}+\epsilon_{x p}^{2}\right] / \epsilon_{x m}^{2}>0 .
$$

It is also evident from the above expression that $\epsilon_{\omega p}$ is larger if $\epsilon_{Q p}^{1}$ is larger, or if $\theta$ is smaller. Thus,

Proposition 5. In a socialist economy with constraints on traded quantities, a decrease in the terms of trade must be accompanied by a particular reduction in the urban wage. Further, the reduction in the urban wage is larger if the peasants' surplus elasticity is larger, or if the net import of the agricultural good is smaller in relation to its urban consumption.

The underlying reason is simple. Lowering the terms of trade leads to a smaller supply of rural.surplus and a larger urban food demand. To balance the demand and supply, therefore, the urban wage must be reduced. Further, the urban wage must adjust more, the greater is the sensitivity of the rural surplus supply to the terms of trade.

The industrial workers thus face a lower price, but also a lower

16. If there are no wage-productivity effects, and if investment is being maximized, then it is easily verified that (15) does not have an interior optimum with respect to $w$; the optimal wage in this case equals the minimum feasible level. 
wage, when the terms of trade are lowered. However, the required lowering of the urban wage always turns out to be sufficiently large that the urban workers become worse-off. To see this, calculate

$$
\frac{d V^{2}}{d p}=\frac{\partial V^{2}}{\partial p}+\frac{\partial V^{2}}{\partial w} \frac{d w}{d p}
$$

which can be expressed as $d V^{2} / d p=\lambda^{2} x^{2} \rho$, where $\rho=-1+\epsilon_{w p} / \alpha_{x}^{2}$. Using (18), note that $\rho=\left[(1-\theta) \epsilon_{Q p}^{1}+\epsilon_{x p}^{2 u}\right] / \alpha_{x}^{2} \epsilon_{x m}^{2}>0$, and hence, $d V^{2} / d p>0$. This result should not be surprising. With a lower price the rural surplus is lower, and at any given level of welfare of urban workers, the urban consumption is higher. Hence, to reduce urban food consumption, the welfare of urban workers must be reduced.

The impact of the terms of trade on the investable surplus is also easily analyzed. Lowering the terms of trade implies lowering the urban wage which, in turn, increases the investable surplus. The effect on productivity, however, is ambiguous, since a lower food price increases productivity; whereas a lower urban wage decreases productivity. The total effect can be obtained from (8), where (18) gives the change in wage and, from (5) and (6), the investment is given by $I=N^{2}\left(Y-w L^{2}\right)+(p-P) T_{x}$. This yields

$$
\frac{d I}{d p}=-N^{2} x^{2}\left[(1-\theta)+\left(\sigma_{p}-\sigma_{m}\right)+\rho\left(1-\sigma_{m}\right)\right] .
$$

Thus, a sufficient condition for a lowering of $p$ to raise the investable surplus is $1 \geq \sigma_{m}$; that is, a dollar increase in the income of an industrial worker raises his net output by no more than a dollar. But, clearly, (19) will be negative so long as $\sigma_{m}$ is not too large compared with one. These results are summarized below.

Proposition 6. In a socialist economy with constraints on traded quantities, a decrease in the terms of trade (i) hurts peasants as well as industrial workers, and (ii) increases investment, provided that wage-productivity effects are not too significant. ${ }^{17}$

17. Also, recall the definition of $\rho$, and observe that it is clear from (19) that, if $\sigma_{m} \geq 1$, then the absolute value of the right-hand side of (19) is larger if $\epsilon_{Q p}^{1}$ is larger. That is, the response of the investable surplus to a change in the terms of trade is larger if peasants' surplus is more price elastic. This should not be surprising, since in the present case a reduction in the terms of trade necessitates a larger decrease in the urban wage. Parallel conclusions need not always hold, however, when external trade is unconstrained. As (11) shows, whether $d I / d p$ increases or decreases with $\epsilon_{Q_{p}}^{1}$ depends on whether peasants are being taxed or subsidized.

Further, it is easy to verify that the qualitative properties of the optimal terms of trade continue to be described by (16) and (17), provided that the tax or subsidy is now defined with respect to the appropriate shadow price; that is, if $s=(p-\eta / \delta) / p$, where $\eta / \delta$ is the shadow price of the agricultral good in terms of the industrial good. 


\section{The Soviet Debate}

The Soviet Industrialization Debate (1924-1928) is important, despite its polemics, because it anticipated some of the difficult but central tradeoffs that confront many of today's developing economies. The overemphasis in this debate on the price squeeze of peasants as a source of the investable surplus, and the underemphasis on the possible increase in the investable surplus through a wage squeeze of the proletariat may not be surprising, given the proproletariat bias of the early Soviet state. Among the positive issues that received insufficient attention in this debate, but that turn out to be central according to our analysis, are the incentives of peasants and proletariat, and the general equilibrium effects of the terms of trade.

Our main interest here is to use our analysis to clarify a "law" and some of the propositions advanced by Evgeny Preobrazhensky [1965] in the Soviet Debate. Specifically he proposed that (i) the state can increase capital accumulation by turning the terms of trade against peasants, and (ii) this can be done without hurting the proletariat. ${ }^{18}$ In an earlier paper [1984] we referred to the above as Preobrazhensky's first and second propositions, respectively. Using our notations, we can rephrase these as (i) $d I / d p<0$, and (ii) $d V^{2} / d p \leq 0$, while $d I / d p<0$. The second proposition is simply a stronger version of the first because it claims not only that the state can increase the investable surplus by lowering the terms of trade, but also that the state can preserve (if not improve) the welfare of the proletariat in this process.

If the economy faces constraints in external trade, then the second proposition is invalid; whereas the first proposition is likely to be valid within a large range of terms of trade (see our Proposition 6). The first proposition may, however, be reversed at low levels of urban wages if a reduction in the terms of trade (and the corresponding reduction in the urban wage) leads, through wageproductivity effects, to significantly large reduction in the net output of the proletariat. The economy obviously has a greater flexibility if its external trade is unconstrained. In this case, as our Proposition 2 shows, the second proposition of Preobrazhensky is

18. Besides the terms of trade, Preobrazhensky discussed many other instruments of policy, such as railroad tariffs, printing money, credit policy, etc. The centerpiece of his verbal analysis, as well as that of his critics, is the terms of trade, on which we have focused here. 
valid if the current terms of trade is above certain levels, and it is invalid otherwise. ${ }^{19}$

Preobrazhensky [1965, p. 124] also advanced what he called the Fundamental Law of Primitive Socialist Accumulation: “... the smaller the inheritance received by the socialist accumulation fund of the proletariat ... when the social revolution takes place, by so much the more, in proportion, will socialist accumulation be obliged to rely on alienating part of the surplus product of presocialist forms of economy and the smaller will be the relative weight of accumulation on its own production basis; that is, the less will it be nourished by the surplus product of the workers in socialist industry."

This "law" appears to claim that a lower current capital stock in industry (a) necessitates the state to put a greater price squeeze on peasants, and (b) implies that the profit from the industrial sector would be a smaller fraction of the total investable surplus. For brevity, we shall refer to the above as Preobrazhensky's third and fourth propositions, respectively. Within our model a smaller current capital stock would imply a larger value of the social weight on investment, $\delta$. With this interpretation the third proposition is correct in the sense that the optimal terms of trade would tend to be lower if $\delta$ is higher (see expression (16), for example). But what this proposition does not recognize is that a price squeeze on peasants beyond some level is counterproductive regardless of the capital stock.

The fourth proposition is also partly correct in the sense that, at given wages and prices, a lower capital stock means that the industrial profit is smaller, and so is the proportion of the total investable surplus coming from industry. However, if the state is willing to trade off the current welfare of the proletariat against its desire for rapid accumulation, then a larger $\delta$ may also imply a lower welfare of the proletariat (principally, though a reduction in their

19. Though it is peripheral to the present analysis, a question that might be of interest is whether an economy with or without constraints on external trade is a more appropriate specification to understand Preobrazhensky's propositions, and which one of the above two specifications is a better representation of the Soviet economy before the debate, that is, during 1918-1924. Our own view (summarized in Sah and Stiglitz [1986]) is that the facts concerning the Soviet Union during this period (such as the trade embargoes and interruptions, and the external credit constraints imposed upon the Soviets) and the understanding that the participants in the Soviet debate had of these facts (for example, the fear of "capitalist encirclement") suggest that, in stylized models such as those being discussed here, a specification with constraints on external trade is more plausible than the one without any constraint. For an opposite view see Carter [1986]. 
wages) and, in this case, it is not necessary for industrial profits to behave the way hypothesized in the fourth proposition.

\section{Collectivization}

Our analysis shows that there is a limit to how low the prices to peasants should be pushed, regardless of whether the state cares for them or not, and there is a corresponding limit to how large a surplus can be extracted from peasants. If a state wants to extract more surplus than this, then it must discover some alternative way of organizing the rural sector. One can interpret the Soviet collectivization as a response to these problems. That is, collectivization was viewed by the Soviet leadership as an organizational alternative which would allow a significantly larger surplus extraction from the rural sector, enabling not only a faster accumulation of capital (deemed by early Soviet leaders to be urgently needed) but also a betterment of the proletariat. ${ }^{20}$

In other words, collectivization can be viewed as a substitution of a supervisory-command system for a price-incentive system. Some aspects of the comparison between the two systems (such as the workers' incentives to shirk under the former) have been extensively studied. Here, we would like to raise an aspect that has received insufficient attention. Most of the literature has focused on a comparison of the ability of alternative organizations to induce workers to achieve certain work norms. But a critical problem, particularly in agriculture (where there are wide variations in the quality of land from plot to plot, and in the climatic conditions from season to season), is the setting of norms. What "should" be the output from a plot of land? How much work is "reasonable" to expect from someone? When individuals work on their own plots, they set the norms for themselves. Also, supervisory systems may work better in a competitive environment because workers can then choose among a variety of farms, where differences in pay may correspond to differences in work norms. But, there is virtually no endogenous basis for norm determination in a collective economy. ${ }^{21}$

20. This, of course, is a purely "economic" interpretation. At the other extreme, one can argue that the reasons for collectivization were entirely "non-economic," such as the commitment of the Soviet state to destroy the power of potentially reactionary peasantry, or simply to abolish private property.

21. This analysis also suggests that productivity in collectives may decline over time (relative to the contemporaneous performance of price-based systems). In early days of a collective, historical productivity may provide a reasonable basis for norm determination; as technology changes, it provides a less and less accurate basis. Moreover, in early days, there may be a cadre of ideologically committed individuals; these individuals may not need much economic incentive; as time progresses, the necessity of economic incentives may increase. 
One possible method of obtaining some of the information that is critical to the determination of norms for different locations is to have private plots in the neighborhood of collectives. Another method is to set contests among collectives such that high performers receive large rewards; whereas low performers receive significant punishment. ${ }^{22}$ Both of these methods may, however, be inconsistent with certain interpretations of socialist ideals.

\section{Distributional Impact of Price Scissors Within the AgRICULTURAL SECTOR}

Our earlier representation that the agricultural sector consists of homogenous peasants is, of course, a simplifying assumption which, though allowing us to focus on the intersectoral aspects, obscures the intrasectoral consequences of changes in the terms of trade. These consequences have often been a source of controversy, and they depend not only on the income and land distribution within agriculture, but also on the induced effects of prices on variables such as the rural wage, migration, reallocation of land entailed by migration, the terms of sharecropping and credit, and the arrangements for sharing work and output within families. For brevity, we focus here on the induced effect on the rural wage but other induced effects can be analyzed similarly.

The importance of the induced effects can be seen as follows. If there were no induced effects, then an increase in food price would hurt the net buyers of food (the landless and the farmers with small land holdings), and help the net sellers of food (large landlords, for example). Quite the reverse may be the case, as we shall see below, if the wage is highly responsive to the food price.

The farm size of a person belonging to the rural group $h$ is $A^{h}$. $Q^{h}$ is his surplus of agricultural good, which can be positive, negative, or zero. $L^{1 h}$ is his net labor supply (that is, labor hours he supplies minus the labor hours employed on his farm). Thus, $L^{1 h}$ is positive (negative) for the net suppliers (demanders) of labor. Also, $A^{h}=0, L^{1 h}>0$, and $Q^{h}<0$, for the landless. An individual's budget constraint is

$$
p Q^{h}+w^{1} L^{1 h}=y^{1 h}>0,
$$

where $w^{1}(p)$ represents the rural wage per hour which, in general, would depend on the terms of trade. Let $\epsilon_{w p}^{1}=d \ln w^{1} / d \ln p$ denote

22. See Nalebuff and Stiglitz [1983], and Lazear and Rosen [1981] for analyses of contests. 
the elasticity of the rural wage rate with respect to $p$. Then, using (20), we see that Roy's identity yields

$$
\frac{d V^{1 h}}{d p}=\lambda^{1 h}\left(\frac{p Q^{h}+w^{1} L^{1 h} \epsilon_{w p}^{1}}{p}\right)
$$

This can be rearranged as

$$
\frac{d V^{1 h}}{d p}=\lambda^{1 h} \frac{\left(p Q^{h}+w^{1} L^{1 h}\right)+w^{1} L^{1 h}\left(\epsilon_{w p}^{1}-1\right)}{p} .
$$

The above expression, in combination with (20), yields the following results.

Proposition 7. A decrease in the terms of trade hurts (i) every rural individual, rich or poor, if the elasticity of the rural wage rate with respect to food price is close to one, (ii) the net sellers (demanders) of labor if the elasticity is significantly greater (smaller) than one. ${ }^{23}$

Clearly, how large or small the elasticity of the rural wage rate is depends on the nature of the labor market and on the labor demand and supply responses of individuals. Here we consider the case in which there are constant returns to scale in agricultural production, and the rural wage rate is determined in a competitive rural labor market; that is, from

$$
\sum_{h} N^{1 h}\left(L^{s h}-A^{h} L^{d}\right)=0,
$$

where $N^{1 h}$ is the number of individuals in the rural group $h$, $L^{s h}\left(p, w^{1}\right)$ is the labor supply of an individual in group $h$, and $L^{d}\left(p, w^{1}\right)$ is the labor employed per unit land. Thus. $L^{1 h}=L^{s h}$ $A^{h} L^{d}$ is the net labor supply.

Denote $\epsilon_{L w}^{d}=-\partial \ln L^{d} / \partial \ln w^{1}$ and $\epsilon_{L p}^{d}=\partial \ln L^{d} / \partial \ln p$ as elasticities of labor demanded on a unit land with respect to wage and price. If the wage rate equals the value of marginal product,

23. It follows, therefore, that if the food-wage hypothesis (see footnote 10) holds in the rural sector, then, a lower term of trade hurts everyone, poor or rich. Further, suppose that we define a "self-sufficient" farmer to be the one who neither buys nor sells labor services; that is, $L^{1 h}=0$. Then it is apparent from (20) and (22) that this farmer is worse-off if the terms of trade are lower. Categories such as self-sufficient farmers and marginal farmers (those who are not landless but are sufficiently poor) have often been used in policy formulations, particularly in India. It should be clear that the boundary lines of such categories, whether defined on the basis of net trade of labor or goods, or on the basis of a given level of welfare (real income), are themselves dependent on wages and prices. 
then the labor demand depends only on the ratio of the wage and output price. Therefore, $\epsilon_{L w}^{d}=\epsilon_{L p}^{d}$. Next, define $\epsilon_{L w}^{s h}=\partial \ln L^{s h} / \partial \ln w^{1}$, and $\epsilon_{L p}^{s h}=-\partial \ln L^{s h} / \partial \ln p$ as elasticities of the labor supply, by an individual belonging to group $h$, with respect to wage and price. A perturbation in (23) then yields

$$
\epsilon_{w p}^{1}-1=\sum_{h} N^{1 h} L^{s h}\left(\epsilon_{L p}^{s h}-\epsilon_{L w}^{s h}\right) /\left(\sum_{h} N^{1 h} L^{s h} \epsilon_{L w}^{s h}+A L^{d} \epsilon_{L w}^{d}\right) .
$$

Substitution of the above into (22) makes it possible to express an individual's gain or loss from a change in the terms of trade solely in terms of the behavioral parameters that, in principle, can be estimated.

Next, note that the right-hand side of (24) is zero either if $L^{\text {sh }}$ is fixed, or if $\epsilon_{L w}^{s h}=\epsilon_{L p}^{s h}$. It is easily verified that the latter happens if the individual's labor supply depends on the food price and on the wage, but not on the price of the industrial good. In both cases, it is obvious that the net labor supply of an individual (and hence of the entire agricultural sector) depends only on the ratio of the wage and the output price. Combining expressions (22) and (24), we find the following.

Proposition 8. A decrease in the terms of trade hurts every rural individual if the rural wage rate equals the value of marginal product and if (i) individuals' labor supplies are fixed, or if (ii) the elasticities of an individual's labor supply with respect to wage and price are close to one another. ${ }^{24}$

Optimal Prices. Our earlier analysis of the optimal terms of trade is easily extended to the present context of heterogeneous rural individuals. If the social welfare in the rural sector is represented as $\Sigma_{h} N^{1 h} W^{1}\left(V^{1 h}\right)$, then (16) continues to describe the optimal terms of trade, where

$$
\beta^{1}=\sum_{h} N^{1 h} \beta^{1 h}\left(\frac{p Q^{h}+w^{1} L^{1 h} \epsilon_{w p}^{1}}{p}\right) / N^{1} Q,
$$

$Q=\Sigma_{h} N^{1 h} Q^{h} / N^{1}$ is the average surplus per agricultural individual, and $\epsilon_{w p}^{1}$ is given by (24). That is, the "average" social weight to be attached to the gains of the rural sector is a weighted average of the

24. This result holds even if the wage rate does not equal the value of marginal product, as long as the labor demand depends only on $w^{1} / p$; that is, it is homogeneous of degree zero in the wage rate and the price. 
marginal social utilities of incomes of different rural individuals, where the weights take into account the induced wage effects. ${ }^{25}$

\section{Pareto-Improving Price Reforms for Cash Crops and AGRICULTURAL INPUTS}

The simplifying assumption that a single (aggregate) good is produced in each of the two sectors underlies the long-standing questions concerning the terms of trade between agriculture and industry, on which we have focused above. Our analysis, however, can be easily extended to incorporate a multitude of goods by interpreting $Q, x$ 's, $p$, and $P$ as vectors. In fact, such a generalization is essential to shed light on such questions as whether fertilizers should be subsidized and tractors taxed or, more generally, how should the taxes and subsidies on various agriculture inputs and outputs be set? These questions are of ongoing concern and controversies in many LDCs.

The effect of a change in the price of the $i$ th good on a rural individual belonging to group $h$ is given by Roy's identity,

$$
\frac{d V^{i h}}{d p_{i}}=\lambda^{1 h}\left(Q_{i}^{h}+L^{1 h} \frac{d w^{1}}{d p_{i}}\right)
$$

where $Q_{i}^{h}$ is this individual's surplus of good $i$. As is obvious, expression (25) is a straightforward generalization of (21). The effects on the welfare of industrial workers and on the investable surplus can also be easily assessed, and using these, one can characterize the optimal prices. Rather than focusing on the analysis of such an optimum (the implementation of which requires knowing, among other things, the distribution of income within each sector, the social weights corresponding to different groups of individuals, the own- and cross-elasticities of the consumption quantities with respect to prices, and the elasticities of the urban and rural wages with respect to various prices), we present here a novel, and more useful, result that shows how Pareto-improving price reforms can be conducted for certain goods on the basis of relatively limited information.

25. The induced wage effects emphasized in this paper are typically absent in the standard tax models (see Atkinson and Stiglitz [1980], for a review) which assume that the general equilibrium effects are insignificant, or that the government can tax wages. Neither assumption is satisfactory in the context of the agricultural sector of an LDC. 
Consider those agricultural inputs and outputs that are not consumed, such as fertilizers, pesticides, agricultural machinery, and various cash crops. For brevity, we refer to these goods as "production goods." Clearly, a change in the prices of these goods does not affect urban individuals, and it affects the consumption and the labor supply of rural individuals only through their full income and through the induced changes in the rural wage. If the $j$ th good is a production good, and $z$ is the vector of inputs and outputs on unit land, then $Q_{j}^{h}=A^{h} z_{j}$, where inputs (outputs) are represented as negative (positive) quantities.

We consider here the case in which the rural wage is determined in a competitive labor market, and assume that all production goods have the same (but not constant) elasticity with respect to wage. ${ }^{26}$ That is,

$$
\frac{\partial z_{j}}{\partial w^{1}}=g_{1} z_{j},
$$

where the parameter $g_{1}$ (as well as $g$ and $B$, which will be used below) are defined in Appendix I, but they are irrelevant for the main result to be derived in this section. Using (26), we show in Appendix I that

$$
\frac{d w^{1}}{d p_{j}}=g z_{j}
$$

That is, the change in the rural wage due to a change in the price of a production good is proportional to the quantity of this production good on unit land. This result holds regardless of the nature of individuals' labor supply and demand responses. Obviously, $g=0$ if the induced wage effects are negligible; in this case, the assumption (26) is not needed. Next, define

$$
c_{j}=-\sum_{i} s_{i} \epsilon_{j i}
$$

where $s_{i}=\left(p_{i}-P_{i}\right) / p_{i}$ represents the rates of taxes of subsidies, and $\epsilon_{j i}=\partial \ln z_{j} / \partial \ln p_{i}$ represents price elasticities of inputs and outputs per unit of land. Thus, (28) represents the proportional change (due to taxation) in the quantity (on unit land) of the production good $j$.

26. This happens if the unit (land) profit function is separable between the price of production goods and other prices; see the Appendix. For details on the underlying production technologies, see Lau [1978]. 
Using (7), (27), and (28), we show in the Appendix that

$$
\frac{d I}{d p_{j}}=\left(c_{j}+B\right) A z_{j},
$$

which provides a basis for the following price reforms.

Consider two production goods, $j$ and $k$. If their prices are changed by $\Delta p_{j}$ and $-\left(z_{j} / z_{k}\right) \Delta p_{j}$, respectively, then it follows from (25) and (27) that the welfare of every rural individual remains unchanged. The resulting change in investment is obtained from (29) as

$$
\Delta I=\left(c_{j}-c_{k}\right) A z_{j} \Delta p_{j} .
$$

The rules for price reforms follow immediately. Calculate $c_{j}$ 's for all of the production goods. If $c_{j}>c_{k}$, and $j$ and $k$ are both outputs (inputs), then increase (decrease) the price of the $j$ th good by a small amount, say $\Delta p_{j}$, and decrease (increase) the price of the $k$ th good by $\left(z_{j} / z_{k}\right) \Delta p_{j}$. Parallel rules apply if the $j$ th good is an output (input) and the $k$ th good is an input (output). The above reforms lead to an unambiguous increase in the investable surplus, without affecting the welfare of any individual. Therefore,

Proposition 9. The above rules of reform are Pareto improving.

The required information to use these rules consists solely of the current taxes on inputs and outputs, current quantities of inputs and outputs on unit land, and the response of these quantities to the changes in the prices of production goods.

Moreover, as should be obvious, our rules of reform take into account the induced effects of price changes on the rural wage, albeit under the assumption (26) which restricts the nature of these effects. If this assumption appears too restrictive, then the relevant empirical question is, how different are the observed induced wage effects from those with the above restriction. If the differences are not significant, then our rules of reform can be employed with significant parsimony in information.

Furthermore, it is obvious from (30) that a necessary condition for the optimality of prices is that $c_{j}$ 's should be equal for all production goods. That is, the proportional reduction due to taxation in the quantities of different production goods (on unit land) should be equal. This has an interesting implication. Assume, for a moment, that changes in the prices of production goods have negligible cross-price effects on the quantities of inputs and outputs 
(that is, $\epsilon_{j i}=0$ if $i \neq j$ ). Then, from (28), $s_{j} \epsilon_{j j}$ is the same for all $j$. Next, from the standard properties of profit functions, $\epsilon_{j j}>0$ for an output, and $\epsilon_{j j}<0$ for an input. Also, from our definition of $s_{j}$, a positive (negative) $s_{j}$ implies a tax (subsidy) on an input and a subsidy ( $\operatorname{tax}$ ) on an output. It follows then that either all of the production goods (inputs as well as outputs) should be taxed or all of them should be subsidized.

This last result is important not because we believe that the cross-price effects are negligible. They are important because they cast doubts on an oft given advice that, on the grounds of equity, some agricultural inputs (like tractors) should be taxed, since they are used primarily by rich farmers, while other inputs (like fertilizer) should be subsidized, since they are used by poor as well as rich farmers. ${ }^{27}$

\section{CONCLUding REMARKS}

A central reason why the terms of trade has received so much attention in the context of intersectoral transfer of resources and accumulation is that an attempt to alter the terms of trade merely requires the government to change the nominal price of the industrial goods. Such changes are more feasible, given the extensive ownership and control that the governments of many developing countries exercise over the industrial sector, than implementing virtually any other policy instrument. This was true in the early Soviet state, and it is true in most of today's LDCs, socialist or not. This is why we have focused in this paper on the terms of trade.

We should emphasize, however, that LDC governments do employ a range of additional policy instruments depending in part

27. The assumption of constant returns to scale in agricultural production, which underlies the preceding analysis, has been repeatedly tested and validated by microeconometric work (see Strauss [1986] for a recent test). Yet an empirical implication of this assumption, which may not always be satisfied by actual observations, is that there are no systematic variations in factor proportions across farmers with different farm sizes. But even if systematic variations in factor proportions are observed, they need not be a consequence of nonhomotheticity of technology (instead, they could result from particular types of heterogeneity of land across farmers, or from unequal access of different individuals to capital and rental markets), nor does the presence of such variations imply that the subsidization of some production goods and taxation of other production goods is useful on the grounds of equity (see Sah and Stiglitz [1987] for further analysis). A quite different set of arguments for fertilizer/tractor/seed subsidies from which our analysis has abstracted is that these subsidies might encourage adoption of new techniques. But the relevant question in this case is whether input subsidies are the appropriate instruments to encourage new techniques, or methods such as provision of usable information to farmers are socially more profitable. 
on the ability of their fiscal bureaucracies, and on the informational and administrative costs of alternative instruments. In some cases, but not always, the analysis of pricing policy is significantly affected by the set of instruments that the government can or cannot employ. An important example is when the government can administer two different sets of prices in the two sectors (for which it needs to have the ability to monitor, at reasonable administrative costs, the movement of goods across sectors); in this case, a change in the prices of goods in one sector does not have a direct effect on individuals in the other sector. ${ }^{28}$

Though we have emphasized in this paper the diversity across different economies concerning some institutional features, such as the external trade environment and the wage determination mechanism, we have abstracted from many other institutional features. Among the important omissions are aspects such as migration of factors across sectors, ${ }^{29}$ and the arrangements of land tenure, credit and intra-household sharing within agriculture. In the sequels to the present paper, we have not only incorporated these institutional features, but have also investigated pricing policies when the set of instruments that the government can employ is wider than that emphasized in this paper. ${ }^{30}$

We have not pursued in this paper some of the important uses to which an analysis such as the present one can be put. For instance, governments often justify the particular policies that they pursue with egalitarian rhetoric. It is important, then, to examine whether significant redistribution from the rich to the poor is possible at all through the set of policy instruments that a government is constrained to employ (or which it chooses to employ). ${ }^{31}$ Our model can also be used (with reasonable values of parameters representing the economy) to identify whether or not the existing policies in a country are consistent with an egalitarian social welfare function. We conjecture that at least in many cases (particularly in those widely prevalent cases in which the government "appears" to subsidize everyone) important inconsistencies will be detected. Whether identifying such inconsistencies is more likely to affect the policy, or the rhetoric, is a moot question.

28. See Sah and Stiglitz [1985c] for the corresponding analysis.

29. Endogenous population migration can be significant not only in the third world LDCs but also in socialist economies, as has been pointed out by Ellman [1979, p. 94].

30. See Sah and Stiglitz [1987] for an overview.

31. Sah [1983] has shown that there are serious limitations on the possibilities of redistribution through commodity taxation and pricing. 


\section{APPENDIX}

Denote the unit profit function as $G=G\left(G^{1}\left(p^{1}, w^{1}\right)\right.$, $\left.G^{2}\left(p^{2}\right)\right)=p z-w^{1} L^{d}$, where $p^{2}$ is the vector of production goods' prices. Then, for the production good $j, \partial z_{j} / \partial w^{1}=-\partial L^{d} / \partial p_{j}=g_{1} z_{j}$, where

$$
g_{1}=\frac{\partial^{2} G}{\partial G^{1} \partial G^{2}} \frac{\partial G^{1}}{\partial w^{1}} / \frac{\partial G}{\partial G^{2}} .
$$

Therefore, the elasticity $\partial \ln z_{j} / \partial \ln w^{1}=g_{1} w^{1}$ is the same for all $j$.

The labor market clearing condition is $\Sigma_{h} N^{1 h} L^{1 h}\left(p, w^{1}\right)=0$, which, upon differentiation, gives

$$
\frac{d w^{1}}{d p_{j}}=-\left(\sum_{h} N^{1 h} \frac{\partial L^{1 h}}{\partial p_{j}}\right) / \sum_{h} N^{1 h} \frac{\partial L^{1 h}}{\partial w^{1}} .
$$

Next, the prices of production goods affect the labor supply only through the full income, $m^{1 h}=w^{1} \bar{L}^{h}+A^{h} G$, where $\bar{L}^{h}$ is the endowment of labor. Thus,

$$
\frac{\partial L^{1 h}}{\partial p_{j}}=\frac{A^{h} z_{j} \partial L^{s h}}{\partial m^{1 h}}-\frac{A^{h} \partial L^{d}}{\partial p_{j}} .
$$

Now, recall that $-\partial L^{d} / \partial p_{j}=g_{1} z_{j}$. It follows that $d w^{1} / d p_{j}=g z_{j}$, where

$$
g=-\sum_{h} N^{1 h} A^{h}\left(g_{1}+\frac{\partial L^{s h}}{\partial m^{1 h}}\right) / \sum_{h} N^{1 h} \frac{\partial L^{1 h}}{\partial w^{1}} .
$$

Using the last expression and the symmetry property $\partial z_{i} / \partial p_{j}=\partial z_{j} / \partial p_{i}$, we can express the derivative of (7) as (29), where

$$
B=-1+(p-P) \sum_{h} N^{1 h}\left[A^{h} \frac{\partial x^{1 h}}{\partial m^{1 h}}-g \frac{\partial Q^{h}}{\partial w^{1}}\right] / A,
$$

and $x^{1 h}$ is the consumption vector for person $h$. Further, $g=0$ if there are no induced wage effects.

YALE UNIVERSITY

PRINCETON UNIVERSITY

\section{REFERENCES}

Atkinson, A. B., and J. E. Stiglitz, Lectures on Public Economics (New York, NY: McGraw-Hill, 1980).

Carter, M., "The Economics of Price Scissors: Comment," American Economic Review (1986), forthcoming. 
Dixit, A. K., and N. Stern, "Determinants of Shadow Prices in Open Dual Economies," Oxford Economic Papers, XXVI (1974), 42-53.

Ellman, M., Socialist Planning (Cambridge: Cambridge University Press, 1979).

Kalhon, A. S., and D. S. Tyagi, "Inter-Sector Terms of Trade," Economic and Political Weekly, XV (1980), A173-184.

Lau, L. J., "Some Applications of Profit Functions," in M. Fuss and D. McFadden, eds., Production Economics: A Dual Approach to Theory and Applications (Amsterdam: North-Holland, 1978), 133-216.

Lazear, E. P., and S. Rosen, "Rank-Order Tournaments as Optimum Labor Contracts," Journal of Political Economy, LXXXIX (1981), 841-64.

Mitra, A., The Terms of Trade and Class Relations (London: Frank Cass, 1977).

Nalebuff, B. J., and J. E. Stiglitz, "Prizes and Incentives: Towards a General Theory of Compensation and Competition," Bell Journal of Economics, XIV (1983), 21-43.

Preobrazhensky, E., The New Economics (Oxford: Clarendon Press, 1965).

Sah, R. K., "How Much Redistribution Is Possible through Indirect Taxes?" Journal of Public Economics, XX (1983), 89-101.

- and J. E. Stiglitz, "The Economics of Price Scissors," American Economic Review, LXXIV (1984). 125-38.

Approach," Journal of Public Economics, XXVIII (1985a), 135-63.

- and - "Price Scissors and the Structure of the Economy," Economic Growth Center Discussion Paper 478, Yale University, 1985b.

- and -, "The Taxation and Pricing of Agricultural and Industrial Goods in Developing Economies," D. O. G. Newbery and N. H. Stern, eds., Modern Tax Theory for Developing Countries (Oxford: Oxford University, 1986).

- and - "The Economics of Town-versus-Country Problems," American Economic Review (1986), forthcoming.

- , and - Peasants versus City-Dwellers: Taxation, Pricing and the Burden of Economic Development, (Oxford: Oxford University Press, 1987).

Stiglitz, J. E., "Alternative Theories of Wage Determination and Unemployment in L.D.C.'s: The Labor Turnover Model," this Journal, LXXXVII (1974), 194227.

- "Alternative Theories of Wage Determination and Unemployment: The Efficiency Wage Model," in M. Gersovitz et al., eds., The Theory and Practice of Development (London: George Allen and Unwin, 1982), 78-106.

-, "Theories of Wage Rigidities," in J. L. Butkiewicz et al., eds., Keynes' Economic Legacy: Contemporary Economic Theories (New York: Praeger, 1986).

Strauss, J., "Does Better Nutrition Raise Farm Productivity," Journal of Political Economy, LXXXXIV (1986), 297-320.

Yellen, J. L., "Efficiency Wage Models of Unemployment," American Economic Review Paper and Proceedings, LXXIV (May 1984), 200-06. 
Copyright of Quarterly Journal of Economics is the property of MIT Press and its content may not be copied or emailed to multiple sites or posted to a listserv without the copyright holder's express written permission. However, users may print, download, or email articles for individual use. 